\title{
A Comparative Analysis of Competency Frameworks for Youth Workers in the Out-of-School Time Field
}

\author{
Femi Vance
}

Published online: 4 August 2010

(C) The Author(s) 2010. This article is published with open access at Springerlink.com

\begin{abstract}
Research suggests that the quality of out-of-school time (OST) programs is related to positive youth outcomes and skilled staff are a critical component of high quality programming. This descriptive case study of competency frameworks for youth workers in the OST field demonstrates how experts and practitioners characterize a skilled youth worker. A comparative analysis of 11 competency frameworks is conducted to identify a set of common core competencies. A set of 12 competency areas that are shared by existing frameworks used in the OST field are identified. The age of youth being served, descriptions of mastery for each competency area, an emphasis on developing mid-level managers, and incorporating research emerge as factors that should be addressed in future competency frameworks.
\end{abstract}

Keywords Youth workers - Competencies · Professional development

\section{Introduction}

Today, nearly 6.5 million children participate in out-of-school time (OST) programs in the United States (Little 2007). The growing OST field is comprised of multiple sectors including after-school, child welfare, civic engagement, college and career assistance, employment and job training, advocacy, and juvenile justice. These diverse sectors offer many types of programs including but not limited to youth development programs, summer camps, internships, mentoring, and prevention and juvenile justice programs (National Institute of Out-of-School Time [NIOST] 2006). Research on OST programs demonstrates their potential to be developmentally enriching contexts where youth can build their academic, social, emotional, and civic skills (Bodilly and Beckett 2005; Durlak and Weissburg 2007; Grossman et al. 2002; Little and Harris 2003; Miller 2003; NIOST 2003; Vandell et al. 2005, 2006). The literature on OST programs also acknowledges the critical

F. Vance $(\bowtie)$

Educational Policy \& Social Context, Department of Education, University of California at Irvine, 3200 Education, Irvine, CA 92697, USA

e-mail: fvance@uci.edu 
role that quality programming plays in realizing these positive outcomes (Charles Stewart Mott Foundation Committee on After School Research and Practice 2005; Hall and Cassidy 2002; Peisner-Feinberg et al. 2000; Rosenthal and Vandell 1996; Vandell and Wolf 2000). Consequently, there has been a proliferation of quality assessment tools, rating systems, and accreditation programs in the OST field to assist programs in self-improvement initiatives. These tools help identify the components of a strong program and consistently skilled staff are identified as a key ingredient to implement high quality programming (Bodilly and Beckett 2005; Tolman et al. 2002).

Unfortunately, multiple barriers hinder the OST field from building a quality, stable pipeline of youth practitioners including high turnover rates, poor compensation and benefits, limited opportunities for upward mobility, and unstable funding. Perhaps the most humbling obstacle is the absence of a recognized definition of the knowledge and abilities that a well trained OST professional should possess (Astroth et al. 2004). In fact, OST scholars and practitioners argue that the first step toward building a well trained workforce is identifying core competencies that youth workers need to deliver quality programs (Stone et al. 2004). In short, core competencies are the knowledge, skills, and abilities used to provide youth with high quality programming. Core competencies can serve as standards of practice for youth workers and can also guide professional development efforts with the ultimate goal of delivering high-quality programs to young people (Starr et al. 2009; Stone et al. 2004).

Developing core competencies for youth workers proves difficult because of the diversity of the OST field (NIOST 2006). To meet the needs of the broadly defined OST field core competencies for youth workers would have to apply to the various sectors of which it is comprised. Multiple versions of youth worker core competencies have been developed as experts struggle to define the professional skill set germane to the OST field. This study reviews existing competency frameworks from different sectors within the OST field to identify the core competencies that span its diverse sectors. Competencies that are common to multiple sectors can provide insight into what experts and practitioners ${ }^{1}$ agree are the necessary knowledge, skills, and abilities that youth workers need to deliver quality programming in any sector of the OST field. The paper begins by reviewing recent literature on the link between program quality and professional development to illustrate the importance of building skills in the OST field and to situate core competencies within this context. Then the barriers to providing opportunities for professional development are explored along with the need for training in the OST field. A description of the core competencies frameworks included in this study is followed by an analysis of the competencies. The paper closes with lessons that can be drawn from the analysis to strengthen future competency frameworks.

\section{Linking Program Quality with Professional Development}

Quality in OST programs is defined by scholars (e.g., Little 2007; Vandell et al. 2004) in terms of structural and process features. Structural quality shapes the context of the program and provides a setting that facilitates implementation of the program model (Vandell et al. 2004). Examples of structural quality features include staff training and experience, program resources, child-staff ratios, and community partnerships. Process quality directly

\footnotetext{
${ }^{1}$ For the purposes of this paper experts and practitioners refer to professionals who work in the OST field delivering services to youth, advocating for youth services, or identifying best practices in the field.
} 
influences children's experience in the program (Vandell et al. 2004). These features include staff-child relationships, peer relationships, and opportunities for autonomy and skill-building. While many factors influence program quality, a well-trained staff is most often reported by experts and practitioners as the key to delivering a quality program (Bouffard and Little 2004; Bowie and Bronte-Tinkew 2006; Dennehy and Noam 2005; Little 2004) and core competencies frameworks can be valuable tools when developing staff training. Staff, in the OST field, have multiple job titles but for the purposes of this paper staff will be referred to as youth workers. A youth worker is "an individual who works with or on behalf of youth to facilitate their personal, social, and educational development and enable them to gain a voice, influence, and place in society as they make the transition from dependence to independence." (Stone et al. 2004, p. 9).

While skilled youth workers are cited as a vital program component there is limited empirical evidence in the OST field linking professional development to program quality or youth outcomes. A possible explanation for this gap in research is that a direct link between staff development and youth outcomes is difficult to isolate among the many features of OST programs that can influence child outcomes. Two studies focusing on the role of quality assurance initiatives in the OST field provide some evidence that staff education and training is associated with program quality. Hall and Cassidy (2002) examined the effects of accreditation on programs and found that improving staff education and training improved the quality of the program, mainly by increasing the number of positive interactions that staff had with youth. In a second study, Rosenthal and Vandell (1996) explored the role of regulatable program features such as ratios and staff background on quality and found that higher levels of staff education was linked to better program quality through positive staff and youth interactions.

Moreover, Rosenthal and Vandell (1996) suggest that the similarity of their findings to the literature in the early childhood field suggest that the findings about program quality may apply to both school-age and early childhood programs. This is particularly noteworthy because research in early childhood provides evidence that supports the claims of OST experts. The early childhood literature shows that highly educated staff and those with more training improve the overall quality of childcare programs and are more apt to design age appropriate activities, identify and meet the diverse needs of program participants, and build positive and supportive relationships with youth (Howes 1997; National Institute for Child Health and Development and Early Child Care Research Network [NICHD ECCRN] 2001; Norris 2001; Peisner-Feinberg et al. 2000; Phillipsen et al. 1997; Vandell and Wolf 2000). Furthermore, early childhood research illustrates the link between professional development and youth outcomes. Studies demonstrated that children whose childcare providers had higher levels of education and training exhibited better cognitive and social competence, used advanced language skills, engaged in more complex and creative learning activities, displayed task persistence and were more cooperative (Howes 1997; NICHD ECCRN 2001; Vandell and Wolf 2000).

The early childhood research also suggests that the effects of professional development on program quality may be similar across contexts and age groups. Studies of the quality of childcare in family dare care homes and infant toddler and preschool classrooms indicate that providers with more formal education and those who received more training provided higher quality care (Norris 2001). For example, Vandell and Wolf (2000) synthesized the literature exploring the relationship between provider characteristics and quality of care in a variety of settings including center-based care, family day care homes, and preschools. The review spanned three different age groups; infants, 
toddlers, and preschoolers. Consistently, more provider education was associated with better quality care. The association between quality of care and provider education and training across contexts and age groups is encouraging because it implies that these findings may be applicable to similar settings such as OST programs and for different age groups such as school-age children and youth.

\section{Professional Development in the OST Field}

Despite some evidence that well trained staff can improve the quality of programs and youth outcomes, hiring trained staff and providing opportunities for professional development for current youth workers is challenging due to workforce issues common in the human services sector, specifically, low wages, minimal benefits, and limited chances for upward mobility (Bowie and Bronte-Tinkew 2006; NIOST \& Academy Educational Development [AED] Center for Youth Development and Policy Research 2003; Community Matters and Breslin 2003). A snapshot of the OST workforce from two studies conducted as part of the Human Services Workforce Initiative provides evidence that these workforce conditions are widespread. Together these studies demonstrate that about $36 \%$ of youth workers have been in their current positions less than a year, the median salary of a youth worker is estimated to be between $\$ 25,000$ and $\$ 30,000$, and approximately 22 percent of youth workers receive benefits (National Afterschool Association [NAA] 2006; Yohalem et al. 2006). These characteristics of the OST field hinder professional development efforts since programs are reluctant to train transient staff and youth workers are reluctant to invest in professional development that is not coupled with wage increases or benefits (Bowie and Bronte-Tinkew 2006). Other threats to improving professional development in the OST field are scarce resources, unstable funding, limited training opportunities and a lack of affordable transportation to training sites (Bowie and BronteTinkew 2006).

Nevertheless, the need for staff education and training is evident. Youth workers rarely enter the field with job specific training. Yohalem et al. (2006) report that less than half of youth workers have experience in related fields such as education, childcare, and social services. That is not to say that youth workers are uneducated. In fact, about two-thirds of youth workers hold a degree or certification, but more often than not these credentials are only tangentially related to the OST field or the jobs that youth workers are currently performing (NAA 2006; Yohalem et al. 2006). While many youth workers have credentials, they are not required to do so to enter the field, which opens OST positions to those that have no pre-service education or training.

Experts and practitioners in the OST field agree that the first step toward building a qualified, stable cadre of youth practitioners is to clearly describe the knowledge and skills necessary to implement high quality programming (Stone et al. 2004). Once defined, a set of core competencies for youth workers could establish standards of practice by helping to set job requirements and providing a way to identify expert practitioners. They can also be used to design education and training programs for youth workers (Astroth et al. 2004). Furthermore, a common set of core competencies would help provide a common language in which to discuss the practice of youth workers, the absence of which has been identified as an issue in the OST field (Madzey-Akale and Walker 2000). A common language about youth worker practice is the foundation for productive discussion about how to build upon and improve current practice. 
The most pressing barriers to the development of a set of core competencies specific to the OST field are fragmented professional development efforts (Astroth et al. 2004) and the diverse sectors within the OST field (NIOST 2006). As a result of isolated professional development efforts multiple versions of core competencies exist in the OST field and yet there is still little understanding of the skills that are applicable to the different sectors (after-school, child welfare, civic engagement, college and careers, and juvenile justice). Starr et al. (2009) bring some research to bear on this issue. They reviewed 14 field-based competency frameworks and compared them on content, structure, and usage in systemlevel initiatives. Their findings suggested considerable agreement in the content of the competency frameworks.

To help move the OST field toward a clearer description of the core competencies that apply to youth workers in different sectors the current study builds off of the research conducted by Starr et al. (2009) and compares the content of competency frameworks that differ from those included in their study. In addition, the current study provides a more in-depth comparative analysis of the competency frameworks. Where Starr et al. (2009) reviewed the competency frameworks in broad strokes, this study incorporates all aspects of the frameworks from competency descriptions to assessment indicators. The intent is to propose a set of youth worker competencies that reflect the consensus of experts and practitioners in the OST field, thereby, offering a common way to conceptualize the skill set necessary to implement quality programming in the diverse sectors of youth work. Based on the limited previous research it is expected that the agreement between competency frameworks will point to a set of competencies that are valued in all sectors of the OST field.

\section{Method}

\section{Selection Process}

Competency frameworks for youth workers are continually being developed. To compare all existing frameworks is beyond the scope of this study. Instead, this study uses a sample of 11 competency frameworks selected to represent the diversity of existing youth worker competencies. These eleven frameworks were chosen using a two step selection process. First, competency frameworks were identified through expert recommendation and internet research, resulting in a sample of nineteen frameworks. From this sample, frameworks were included in the analysis if they provided descriptions of each competency area that were detailed enough to provide a general description of the skill. Eleven competency frameworks were included in the final sample and were considered in the comparative analysis. There is a subset of five frameworks that overlap with the sample used by Starr et al. (2009), which speaks to the prominence of these frameworks within the OST field. The current study should be considered exploratory given that it examines a small sample of the available competency frameworks.

The 11 frameworks included in the sample were developed by varied sources including government agencies, youth advocacy organizations, professional development organizations, and youth policy research firms. For a list of the chosen competency frameworks and their sources see Table 1. The selected competency frameworks also represent the diversity of the OST field. Some of the following frameworks were designed to address the needs of youth workers in specific sectors of the OST field such as youth development programs, 
Table 1 List of youth worker competency frameworks

Source Competency framework title

\section{Government}

Department of Defense

Indiana state with the Indiana YouthPRO Association

U.S Department of Labor with the Sar Levitan Center

Kansas and Missouri with the Missouri Afterschool Network, the Opportunities in a Professional Education Network Initiative, and the Kansas Enrichment Network.

New York with Cornell University and Afterschool Works! New York

Massachusetts Department of Early Education and Child Care

Youth Advocacy Organizations

National Collaboration for on Workforce and Disability for Youth (NCWD/Youth)

Professional Development Organizations

Advancing Careers through Education and Training (ACET)

Commonwealth Youth Programme

Youth Policy and Research Firms

Academy for Educational Development (AED)

National Collaboration for Youth
School-Age Staff Training Program

Indiana Youth Development Credential Core Competencies

Youth Development Practitioner Apprenticeship Core Skills

Bi-State Core Competencies for Youth Development Professionals

New York School-Age Care Credential Core Competencies

Core Competencies for Early Education and Care and Out-of-School Time Educators

NCWD/Youth Knowledge, Skills, and Abilities

ACET School-Age Professional Core Competencies

Commonwealth Youth Programme Modules

AED Core Competencies for National YouthServing Organizations

Youth Development Worker Core

Competencies

after-school programs, college and career development, employment and job training and others were designed to be applicable to youth work in general.

The competency frameworks differed in the features that they offered. The more thorough frameworks included descriptions of the competency areas and identified goals of each area, provided behavioral indicators of progress, supplied tools for assessment, and explicitly related competency areas to the daily practices of youth workers. In addition to representing a variety of sources, sectors, and designs, the chosen frameworks also highlight core competencies developed by institutions that have been cited as leaders in the OST field and/or have exhibited an innovative approach in developing their core competencies.

\section{Competency Framework Descriptions}

Below are descriptions of each of the core competency frameworks included in the final analysis. The frameworks are organized into categories by source (government, youth advocacy organizations, professional development organizations, and youth policy and research firms). The following descriptions are meant to provide brief background information about each competency framework. ${ }^{2}$

2 Detailed summaries of the key features and competency areas of each framework can be provided upon request from the author. 


\section{Government $^{3}$}

School-age staff training modules. One of the most acclaimed OST training systems is the Department of Defense (DoD) professional development system for childcare workers. This system was created under the Military Child Care Act of 1989 (Campbell et al. 2000) and remains a model for states, localities, and organizations seeking to start a new professional development system for youth workers. The competency framework that was developed as a part of the DoD professional development system includes 15 training modules to guide the practice of youth workers implementing programs for school-age youth (6-12 years old) on military installations (Department of the Air Force 1998). DoD youth workers can also provide programming for older youth for short periods of time such as summer or spring breaks (Department of the Air Force 1998). The DoD training modules are designed to build upon one another. The 15 modules contain pre and post selfassessments, brief case studies for analysis, and activities to support development of skills in the competency area. Each module also has learning objectives that must be achieved by the youth worker before advancing to the next one. All DoD youth workers are required to complete the training modules within 18 months of being hired (Department of the Air Force 1998).

Core competencies for the Indiana youth development credential. Indiana developed a state Youth Development Credential (IYD) to meet the growing demand for trained staff in the expanding OST field (Indiana YouthPRO Association 2007). Using a grant from the Indiana Child Care Fund the Indiana YouthPRO Association was commissioned to spearhead the development of the IYD using expertise from practitioners and organizations throughout the state (Indiana YouthPRO Association 2007). Core competencies are an integral part of the credentialing process and are intended to represent best practices for professionals working with school-age youth in structured programs. Applicants must complete training hours in the competency areas, document their progress in each competency areas in a portfolio, and demonstrate proficiency in the competency areas to an advisor and an expert in the field. The competencies designed for the IYD are separated into five general areas with a total of 16 competencies (Indiana YouthPRO Association 2007). Each competency area is further divided into functional areas that correspond to behavioral indicators that can be used for assessment (Indiana YouthPRO Association 2005).

Youth development practitioner apprenticeship core skills. The Youth Development Practitioner Apprenticeship (YDPA) initiative is a national program created by the U.S. Department of Labor to improve the youth service workforce by providing apprenticeship programs that addressed the need for performance standards, training, and career paths (Sar Levitan 2001; United States Department of Labor 2009). The Sar Levitan Center was commissioned to develop practical tools to guide training for youth workers providing direct services to youth. With input from practitioners and advocates in the youth development field, the Sar Levitan Center designed the YDPA Skill Areas (Sar Levitan 2001). The Sar Levitan Center identified three major skill areas in the youth development field: Core Skills, Workforce Development, and Administrative Skills (Sar Levitan 2001). These skill areas served as the foundation for the national movement to improve training in youth

\footnotetext{
3 Some frameworks were developed by organizations outside of government agencies. These agencies developed the competencies on behalf of the local, state, or federal government and for the purposes of this paper the developed frameworks will be considered as originating from a government agency. Where appropriate a description of the organization that authored the competencies is provided.
} 
work and provided support for organizations that operate their own apprenticeship programs. In addition, these skill areas supported the development of future competency frameworks (Astroth et al. 2004; McCain et al. 2004). This study focuses on the 28 Core Skills that were developed for the YDPA initiative. The set of Core Skills included a recommended number of training hours for each skill that ranged from as low as $3 \mathrm{~h}$ to a high of $26 \mathrm{~h}$.

Kansas and Missouri bi-state core competencies for youth development professionals. Kansas and Missouri partnered to author the first set of bi-state core competencies for youth development professionals. The impetus for the development of the bi-state competencies was research indicating the link between trained staff, quality programs, and youth outcomes as well as a need to define a professional identity for the OST field (Opportunities in a Professional Education Network [OPEN] Initiative, Missouri Afterschool Network [MASN], \& Kansas Enrichment Network [KEN] 2006). The task of developing the core competencies was outsourced to three leading OST organizations, OPEN Initiative, the MASN, and the KEN. Together these organizations convened workgroups and conducted an online survey with practitioners to guide the content of the competencies. The resulting competency framework addresses the skills of youth development professionals who serve a diverse population of school-age children and older youth and their families (OPEN, MASN, \& KEN 2006). The Bi-state Core Competencies are organized into eight content areas with five successive levels of mastery commiserate with educational attainment (OPEN, MASN, \& KEN 2006). The first three levels of mastery are geared toward training effective front line youth workers while the higher two levels highlight the knowledge and skills needed for mid-level managers and administrators.

New York state school-age credential core competencies. Collaboratively, AfterSchool Works! New York (formerly the New York State School-Age Coalition), Cornell University, and the New York State Office of Children and Family Services (2000) developed the state school age credential to promote quality youth services. The credential began in 2000 as one component of a statewide school-age training initiative. To earn the New York State School Age Credential candidates must demonstrate proficiency in 14 skill areas that were modeled after the U.S. Army School-Age Credential and illustrate the skills required to implement high quality after-school programs (AfterSchool Works! New York 2009). The credential is seen as a work in- progress and revisions are led by AfterSchool Works! New York in consultation with a the Statewide Credential Workgroup (AfterSchool Works! New York 2009). This paper focuses on the 14 skill areas that are at the core of the school-age credential.

Core competencies for early education and care and out-of-school time educators. The Massachusetts Department of Early Education and Child Care (MDEECC) developed a set of core competencies that is unique in that it targets early education and care as well as a significant portion of school-age activities. The core competencies were designed to guide skill development in professionals that work with youth from birth to age 14 and up to age 16 for youth with special needs (MDEECC 2010). The core competencies were informed by research and accreditation standards garnered from national programs such as Head Start and local organizations such as the former Massachusetts School-Age Coalition (MSAC) (MDEECC 2010). A task force comprised of over 50 practitioners, researchers, trainers, and community partners convened to identify the eight core competency areas deemed essential for working with children and youth. The competency framework uses a three level rating system to describe the skills that different types of staff members should exhibit within each competency area. The initial level is for youth workers who assist with 
program activities, the mid-level targets staff members who work directly with children or youth, and the advanced level is aimed at administrators such as site coordinators and directors. The eight core competencies and the rating system are described in a report that also illustrates the alignment between the core competencies and Massachusetts state quality initiatives for youth programs (MDEEC 2010).

\section{Youth Advocacy Organizations}

National collaborative on workforce and disability for youth knowledge, skills, and abilities. The National Collaborative on Workforce and Disability for Youth (NCWD/Youth) is dedicated to supporting youth with disabilities through high quality services that move youth toward employment and independent living (McCain et al. 2004). One of the goals of the NCWD/Youth is to "improve the awareness, knowledge, and skills of individuals responsible for providing direct service to youth" (McCain et al. 2004, p. 1). In pursuit of this goal, the organization partnered with the National Youth Employment Coalition to establish a list of core competencies for youth workers (McCain et al. 2004) with an emphasis on those employed in the workforce development system. The NCWD/Youth broadly defines the workforce development system to include professionals that work as job developers, school counselors, youth development program staff and independent living skill specialists. The NCWD/Youth competency framework was based on a literature review of more than 70 professional development initiatives for frontline youth workers. The final competency framework focuses on the needs of youth between the ages of 14-25, and includes a set of 10 knowledge, skills, and abilities (KSAs) to serve all youth.

\section{Professional Development Organizations}

Advancing careers through education and training school-age professional core competencies. Advancing Careers through Education and Training (ACET) is a nonprofit professional development organization based in Georgia that is committed to improving the quality of childcare and youth programs through support of the professionals that implement programs (ACET n.d.). The competencies developed by ACET span the early childhood and school-age field and were meant to apply to youth workers in childcare centers, preschools, pre-kindergarten programs, family day care, group homes, and schoolage care programs (ACET 1995). A group of leaders and stakeholders in early education and school-age programs developed the first competency frameworks in 1995 (ACET 2007). By 2006, the competency frameworks were revised to reflect new knowledge garnered from research and practice (ACET 2007). The revision process included a review of research and best practices in the field as well as feedback from leaders and practitioners gathered through surveys and focus groups (ACET 2007). The resulting framework has seven school-age core competencies that are further clarified by supporting behavioral indicators. The framework also delineates the core competencies for administrators and provides examples of beginning, intermediate, and advanced levels of competence (ACET 2007). This paper focuses on the competencies for school-age care that prepare youth workers to serve early school-age children (5-6 years) to early adolescents (10 and older).

Commonwealth youth programme youth development diploma modules. The Commonwealth Youth Program (CYP) is an international development organization that seeks to empower youth ages 15-29. CYP has a presence in four geographic regions, Africa, Asia, the Caribbean, and the Pacific representing countries such as Nigeria, India, Jamaica, England, and Australia (CYP 2006a). The mission of CYP includes improving the quality 
of youth services thus, CYP offers a Youth Development Diploma that has a presence in 45 countries through partnerships with 27 local institutions (CYP 2006a). The Diploma is delivered using distance learning as a way to extend the reach of the educational program and to allow students to tailor the program to their needs. The content of the Diploma was developed through consultation with experts in the youth development field in the four geographic regions and was designed to provide youth workers with a knowledge base to inform their practice (Nonyongo 2006). The Diploma provides an international perspective of which competencies are relevant to the youth development field. The Diploma consists of 13 core modules plus any region specific modules that are introduced by local partnering organizations (CYP 2006a). Each module takes between 4 and 6 weeks to complete and the students can complete the entire program in up to 18 months (CYP 2006b). This study uses the 13 mandatory modules as the core competencies for the youth development diploma.

\section{Youth Policy and Research Firms}

Academy for educational development competencies for national youth serving organizations. The Academy for Educational Development (AED) Center for Youth Development and Policy Research was a leading player in the Stronger Staff-Stronger Youth initiative that had the goal of improving professional development for youth workers (Astroth et al. 2004). As part of the Stronger Staff-Stronger Youth initiative AED convened a workgroup that represented 25 national youth serving organizations (AED 1996; Astroth et al. 2004). The Core Competencies for National Youth-Serving Organizations was the brainchild of this workgroup and was informed by interviews and surveys with more than five hundred youth workers. The work group defined core competencies as, "the demonstrated capacities that allow a youth development worker to be a resource for youth, organizations, and communities" (AED 1996; p. 1). This definition and the 10 competencies described in the resulting framework represents one of the early attempts to define and identify competencies for youth workers.

National collaboration for youth core competencies for youth workers. The National Collaboration for Youth (NCY) is the membership based youth advocacy arm of the National Human Services Assembly. The coalition has been active for the past 30 years and has grown to over fifty member organizations. The mission of NCY is to provide a strong, unified voice to help improve the condition of young people (NCY n.d.). The NCY appointed a task force comprised of representatives from national youth serving organizations such as Boys and Girls Clubs of America and YMCA to develop a set of core competencies (Astroth et al. 2004) that would address the skills needed by front line staff and volunteers to implement effective programs (NCY 2004). That task force used reviews of earlier competencies (e.g., YDPA) and competencies identified by member organizations to inform the development and design of their framework (Astroth et al. 2004). In addition, a working draft of the competencies was distributed to select member organizations with the goal of improving the flexibility of the document so that it could be used in the diverse settings encountered within the OST field. The final framework outlines 10 competencies for entry-level youth workers that are supported by behavioral indicators. The competency framework sets itself apart from other frameworks by using accessible language and encouraging modification to facilitate organizational usage. The NCY also developed an observation tool and rating scale to accompany the competency framework. 


\section{Analysis of Competency Frameworks}

A comparative analysis of the 11 competency frameworks was used to identify core competencies common to multiple sectors in the OST fields. The analysis incorporates all aspects of the competency frameworks including competency descriptions and goals, content areas, assessment indicators, and mastery levels in identifying overlap between the competency frameworks. For example, the DoD School-Age Staff Training Program does not dedicate a module to child and youth development. However, this topic is integrated into several modules such as communication, positive guidance, and out-of-school environments. Each module in the training program also outlines the stages of child development relative to the topic of that module. Thus, this framework is considered to include an understanding of child and youth development as a competency area.

The comparative analysis was conducted in two stages. First, a table identifying the competency areas included in each of the studied frameworks was developed. The table helped pinpoint which competency areas are shared by the studied frameworks. To refer to the table during the description of the comparative analysis please see Table 2 . Numerous competency areas were included in each of the frameworks, making it difficult to include each competency area in the table. Consequently, competency areas that were featured in only one framework were omitted from the table. Three frameworks included unique competency areas that were omitted from the table. These frameworks are: (a) the YDPA Core Skills; (b) the NCWD/Youth Knowledge Skills and Abilities; and (c) the Commonwealth Youth Programme Youth Development Diploma Modules. A list of the omitted competency areas appears in Table 3.

While the omitted categories are different in each of the three frameworks, a number of them focus on skills that help youth transition into adulthood such as education and training, workforce preparation, and promoting enterprise and economic development. This is not unexpected since the frameworks developed by the Commonwealth Youth Programme and the NCWD/Youth focus on older youth and young adults. The YDPA does not specify a target age group, yet, it includes adolescent psychology and youth and adult counseling as competency areas suggesting that this framework also emphasizes the needs of older youth and young adults.

In the second stage of the analysis, the table was used to establish levels of agreement between frameworks. Agreement on core competencies was classified into two levels: substantial agreement and agreement. Substantial agreement was accomplished when at least 80 percent of the considered frameworks included a particular competency area and agreement was achieved when $60-79 \%$ of the considered frameworks included a particular competency area. If a competency area was included in less than $60 \%$ of the frameworks it was not considered a common competency area.

\section{Results}

The 11 frameworks used in the analysis represent a variety of sectors and sources, emphasize different age groups, and varied in style, detail, and organization. The analysis showed a marked difference between the competency frameworks that focused on older youth (The Commonwealth Youth Programme Modules and the NCWD/Youth Knowledge, Skills, and Abilities) and the remaining competency frameworks. Specifically, these two frameworks focused on youth whose ages extended beyond school-age. The Commonwealth Youth Programme Modules were developed for youth ages 15-29 and the 
Table 2 Summary of competency frameworks

\begin{tabular}{|c|c|c|c|c|c|c|c|c|c|c|c|}
\hline \multirow[b]{2}{*}{$\begin{array}{c}\text { Core Competencies } \\
\text { Areas }\end{array}$} & \multicolumn{11}{|c|}{ Competency Frameworks } \\
\hline & 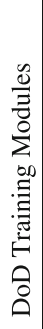 & 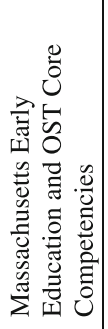 & 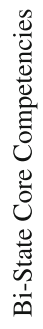 & 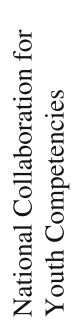 & 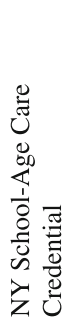 & 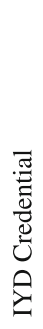 & 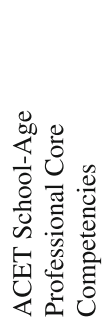 & 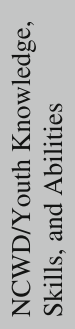 & 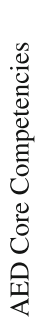 & 艺 & 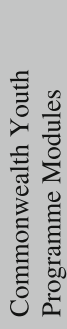 \\
\hline $\begin{array}{l}\text { Child/Youth } \\
\text { Development }\end{array}$ & $\bullet$ & $\bullet$ & $\bullet$ & $\bullet$ & $\bullet$ & $\bullet$ & $\bullet$ & $\bullet$ & $\bullet$ & $\bullet$ & $\bullet$ \\
\hline Positive Guidance & $\bullet$ & $\bullet$ & $\bullet$ & $\bullet$ & $\bullet$ & $\bullet$ & $\bullet$ & & $\bullet$ & $\bullet$ & $\bullet$ \\
\hline $\begin{array}{l}\text { Families \& } \\
\text { Communities }\end{array}$ & $\bullet$ & $\bullet$ & $\bullet$ & $\bullet$ & $\bullet$ & $\bullet$ & $\bullet$ & $\bullet$ & $\bullet$ & $\bullet$ & $\bullet$ \\
\hline Program Management & $\bullet$ & $\bullet$ & $\bullet$ & & $\bullet$ & $\bullet$ & $\bullet$ & $\bullet$ & $\bullet$ & $\bullet$ & $\bullet$ \\
\hline Professionalism & $\bullet$ & $\bullet$ & $\bullet$ & $\bullet$ & $\bullet$ & $\bullet$ & $\bullet$ & & $\bullet$ & $\bullet$ & \\
\hline *Communication & $\bullet$ & $\bullet$ & $\bullet$ & $\bullet$ & $\bullet$ & $\bullet$ & $\bullet$ & & & $\bullet$ & \\
\hline Safety & $\bullet$ & $\bullet$ & $\bullet$ & $\bullet$ & $\bullet$ & $\bullet$ & $\bullet$ & & & & \\
\hline Health & $\bullet$ & $\bullet$ & $\bullet$ & & $\bullet$ & $\bullet$ & $\bullet$ & & & $\bullet$ & $\bullet$ \\
\hline Physical & $\bullet$ & $\bullet$ & $\bullet$ & $\bullet$ & $\bullet$ & $\bullet$ & $\bullet$ & & & & \\
\hline Self & $\bullet$ & $\bullet$ & $\bullet$ & $\bullet$ & $\bullet$ & $\bullet$ & $\bullet$ & & & & \\
\hline Diversity & & $\bullet$ & $\bullet$ & $\bullet$ & & $\bullet$ & $\bullet$ & & $\bullet$ & $\bullet$ & $\bullet$ \\
\hline Curriculum & & $\bullet$ & $\bullet$ & $\bullet$ & & $\bullet$ & $\bullet$ & & $\bullet$ & $\bullet$ & \\
\hline${ }^{*}$ Cognitive & $\bullet$ & $\bullet$ & $\bullet$ & & $\bullet$ & $\bullet$ & $\bullet$ & & & & \\
\hline *Social & $\bullet$ & $\bullet$ & $\bullet$ & & $\bullet$ & $\bullet$ & $\bullet$ & & & & \\
\hline Creative & $\bullet$ & & $\bullet$ & & $\bullet$ & $\bullet$ & $\bullet$ & & & & \\
\hline Observation/Assessments & $\bullet$ & $\bullet$ & $\bullet$ & & & $\bullet$ & & $\bullet$ & & $\bullet$ & \\
\hline $\begin{array}{l}\text { Out-of-School } \\
\text { Environments }\end{array}$ & $\bullet$ & $\bullet$ & $\bullet$ & & $\bullet$ & $\bullet$ & & & & & \\
\hline Child Abuse & $\bullet$ & $\bullet$ & $\bullet$ & $\bullet$ & & & $\bullet$ & & & & \\
\hline Cooperative Learning & & $\bullet$ & $\bullet$ & & & $\bullet$ & & & $\bullet$ & $\bullet$ & $\bullet$ \\
\hline Facilitation & & $\bullet$ & $\bullet$ & & & & & & $\bullet$ & $\bullet$ & $\bullet$ \\
\hline Interactions with Youth & $\bullet$ & $\bullet$ & $\bullet$ & $\bullet$ & & & & $\bullet$ & $\bullet$ & & \\
\hline Teamwork & & $\bullet$ & $\bullet$ & $\bullet$ & & & & & $\bullet$ & $\bullet$ & \\
\hline Problem Solving & & & & & & $\bullet$ & & & & $\bullet$ & \\
\hline Literacy & & & & & & $\bullet$ & & & & $\bullet$ & \\
\hline $\begin{array}{l}\text { Youth with Special } \\
\text { Needs }\end{array}$ & & & & & & & & $\bullet$ & & $\bullet$ & \\
\hline
\end{tabular}

Shaded competency frameworks created for youth whose ages extend beyond school age, Bold Substantial Agreement, Italics Agreement, *, affected with restricted sample

a Multiple frameworks mentioned meeting the needs of all youth including those with special needs. However, the frameworks developed by YDPA and NCWD/Youth were the only that included a separate competency area(s) for youth with special needs. This competency includes the training and development of youth with disabilities

NCWD/Youth competency framework targets youth 14-25 years old. The remaining competencies focused on school-age youth or those who are between the ages of 5-18. To illustrate how the target age group can influence the skills needed for youth workers the analysis will present two sets of agreed upon competencies. The first set will identify the common skills between all of the competency frameworks. The second set will highlight the common skills between the frameworks that focus only on school-age youth. 
Table 3 List of omitted competency areas by framework

\begin{tabular}{cc}
\hline & Omitted competency areas \\
\hline $\begin{array}{c}\text { Youth Development Practitioner } \\
\text { Apprenticeship Core Skills }\end{array}$ & Group Work, Group Dynamics, Sociology, Adolescent Psychology, \\
& Youth and Adult Counseling, Life Skills, Grief Counseling, \\
& Knowledge of Youth Legal System, Education and Training, \\
& Training Materials Development, Motivational Skills, and Service \\
& Learning \\
NCWD/Youth Knowledge, Skills & Workforce Preparation, Career Exploration, Relationship Between \\
and Abilities & Employer and Employee, Administrative Skills \\
Commonwealth Youth Programme & Learning Process, Principles and Practice of Youth Development \\
& Work, Gender and Development, Policy Planning and \\
& Implementation, Promoting Enterprise and Economic \\
& Development, Sustainable Development and Environmental \\
& Issues \\
\hline
\end{tabular}

Teasing out only the core competencies that achieved substantial agreement or agreement among all of the studied frameworks results in the following list of common core competency areas ${ }^{4}$ :

\section{Substantial Agreement}

- Child/Youth Development — understands the principles of child and youth development and applies them to the implementation of the program.

- Positive Guidance-uses positive guidance techniques to manage the behavior of youth.

- Families and Communities - builds relationships with families and other organizations in the community that encourage support of and involvement in the program.

- Program Management-demonstrates management skills that are necessary for program implementation such as resourcefulness and time management.

- Professionalism - acts in a professional manner by following program policies and shows a commitment to professional growth by pursuing opportunities to enhance skills.

\section{Agreement}

- Safety-maintains a program environment that minimizes the risk of injury to youth and teaches youth to develop habits that help ensure their safety.

- Health-instructs youth in and encourages behaviors that promote wellness.

- Physical-manages the program environment to meet the physical needs of youth while providing opportunities that foster physical development.

- Communication-interacts with youth in ways that build upon and encourages development of strong communication skills.

- Self-helps youth explore their interests and abilities while nurturing good self-esteem.

\footnotetext{
${ }^{4}$ The definitions of the competency areas summarize the descriptions provided by the eleven competency frameworks.
} 
- Diversity-creates a bias free environment that reflects the diversity (cultures, religions, race, sexual orientation etc.) of participants and provides activities that explore differences between individuals.

- Curriculum-designs program activities that meet the needs of the youth and encourage youth to grow in key developmental areas.

When the competency frameworks that target older youth are excluded the list of common core competencies areas changes slightly. Competencies that graduated from agreement to substantial agreement are marked with an asterisk. Those that are new to the list are written in bold.

\section{Substantial Agreement}

- Child/Youth Development—understands the principles of child and youth development and applies them to the implementation of the program.

- Positive Guidance-uses positive guidance techniques to manage the behavior of youth.

- Families and Communities_-builds relationships with families and other organizations in the community that encourage support of and involvement in the program.

- Program Management-demonstrates management skills that are necessary for program implementation such as resourcefulness and time management.

- Professionalism - acts in a professional manner by following program policies and shows a commitment to professional growth by pursuing opportunities to enhance skills.

- Communication*-interacts with youth in ways that build upon and encourages development of strong communication skills.

\section{Agreement}

- Safety-maintains a program environment that minimizes the risk of injury to youth and teaches youth to develop habits that help ensure their safety.

- Health-instructs youth in and encourages behaviors that promote wellness.

- Physical-manages the program environment to meet the physical needs of youth while providing opportunities that foster physical development.

- Cognitive-provides learning opportunities and interacts with youth in ways that support cognitive development in youth.

- Self-helps youth explore their interests and abilities while nurturing good self-esteem.

- Social-helps youth develop peer relationships, practice appropriate group behaviors, and encourages respect for others.

- Diversity-creates a bias free environment that reflects the diversity (cultures, religions, race, sexual orientation etc.) of participants and provides activities that explore differences between individuals.

- Curriculum-designs program activities that meet the needs of youth and encourage youth to grow in key developmental areas.

The results of this analysis are presented in Table 2. The table identifies the competencies areas that are included in each framework and highlights the competency areas that achieved substantial agreement (presented in bold text) and agreement (presented in italics). The competency areas that were affected by the exclusion of the frameworks targeting older youth are marked with an asterisk. 


\section{Discussion}

The purpose of this paper was to identify a common skill set among the myriad knowledge and skills that experts and practitioners endorse as important to implementing high quality youth services. Ideally, this common set of youth worker competencies would represent the skills for youth workers in multiple sectors within the OST field. It was posited that a common set of youth worker skills would emerge. A comparative analysis of a sample of eleven competency frameworks representing youth work broadly and the multiple sectors within the OST field (youth development programs, employment and job training, schoolage programs) was conducted to understand if common skill areas could be identified.

The exploratory analysis revealed overlap between the existing core competencies for youth workers in different sectors. In addition, the common core competency areas that were identified in this study almost mirror those found in a similar analysis conducted by Starr et al. (2009) using an alternate sample of frameworks. A difference between the current findings and those by Starr et al. (2009) is that the competency area concerning program environment was not included among the list of common core competencies. This suggests that future analysis should pay particular attention to the prominence of this competency area. There was only one other minor difference. Starr et al. (2009) identified two "universal" competencies or those present in all of the studied frameworks: Curriculum and Professionalism. In this study, the universal competencies were Understanding Child and Youth Development and Building Relationships with Families and Communities. Universal competencies from field-derived frameworks highlight what experts view as fundamental to the OST field. More research on competency frameworks is needed to identify the universal competencies.

The exploratory analysis also demonstrated that age, not the sector of youth work, was the driver for the differences between frameworks. Some of the frameworks focused on school-age youth, generally 6-18 years of age, and others focused on older youth ranging from ages 14-29. To accommodate the differences in the competency frameworks due to the age of youth to be served, two lists of common core competencies were presented, one that represented all of the frameworks and another that reflected frameworks designed for working with school-age youth.

The differences between the two lists of common core competencies demonstrate that the frameworks focused on school-age youth emphasize the ability of the youth worker to facilitate growth in key developmental areas (e.g., physical, cognitive, communication, social, etc.) Alternatively, as illustrated during the discussion of the omitted competencies, the two frameworks focusing on older youth emphasized the need for youth workers to facilitate the transition into adulthood, requiring skills such as encouraging career exploration, monitoring employer and employee relations, and nurturing an entrepreneurial spirit in youth.

The frameworks targeting school-age youth and those for older youth spanned a common age range (ages 14-18). Despite this overlap in the age range the frameworks developed to serve school-age youth rarely included skills that would help youth transition into adulthood. Omitting these competencies in school-age frameworks may hinder the ability of youth workers to properly serve older youth. Future competency frameworks for school-age youth may want to include competencies that prepare youth between the ages of 14-18 for their transition into adulthood. One method of doing so would be to incorporate competencies that are relevant for youth ages 14-18 into the common core competency areas developed to serve only school-age youth (the second list of competency areas presented). For example, managing relationships between employers and employees could 
be incorporated into the Social competency area. Or the Self competency area could include aspects of career exploration. Overall, acknowledging that a specific set of competencies may be needed to serve older youth will help experts and practitioners develop frameworks that will better serve the needs of all youth.

There were several core competency areas that did not qualify for inclusion in either the substantial agreement or agreement categories (did not meet the $60 \%$ criterion) because they were not identified by enough frameworks (see Table 2). Arguably, some of the excluded competencies could be included as a topic in one or more of the common core competencies. For instance, Child Abuse was and excluded competency area that could be included as a topic in the Safety competency area. Similarly, Out-of-School Environments may fit nicely as a topic in the Program Management competency area. This may suggest that some skills may not warrant their own competency area but are still applicable to youth work and can be incorporated by broadening the definition of some of the common core competencies.

\section{Implications for Practice}

There were three key lessons garnered from the analysis of the competency frameworks. Like the analysis, these lessons draw from all characteristics of the competency frameworks including competency descriptions and goals, content areas, assessment indicators, and mastery levels. The lessons are meant to serve as guiding principles for expanding upon the common core competencies proposed in this study. First, very few frameworks included levels of mastery for each competency area (see Bi-State Core Competencies for Youth Development Professionals, MDEECC Core Competencies for Early Education and Care and OST Educators, Youth Development Worker Core Competencies observation assessment tool, and ACET School-Age Care Professional Core Competencies). The lack of mastery levels was also noted by Starr et al. (2009) who found that less than half of the competency frameworks included in their sample had this feature. Including levels of mastery in competency frameworks can be valuable. As individuals, staff will progress in the competency areas at their own pace and outlining levels of mastery can help demonstrate to staff the competency areas in which they are strong and those that may need improvement. Furthermore, defining levels of mastery will increase the likelihood that staff that reach the highest level of mastery will possess the same skills and be able to accomplish the same tasks, adding to the ability of a competency framework to set the standard for a skilled youth worker.

Second, the current competency frameworks are geared toward front line staff and as a whole largely ignore the training needs of mid-level management and administrators. Starr et al. (2009) also found few frameworks that included competencies for these staff members. Only three of the fourteen frameworks that they studied addressed the needs of supervisory staff. However, research indicates that the practice of managers is related to the quality of staff practice (Smith et al. 2009). Ideally, managers and administrators would have a firm grasp on the skills needed to be a front line staff. However, they will need to develop additional skills to run quality programs. Smith et al. (2009) found that managers who conduct formal observations of staff, led data driven program improvement efforts, and participated in trainings to improve youth worker practice had staff who implemented higher quality programs.

Not all of the studied frameworks lacked adequate emphasis on the skills needed by mid-level managers and administrators. The Bi-State Core Competencies for Youth 
Development Professionals and the MDEECC Core Competencies for Early Education and Care and OST Educators used innovative approaches to address the needs of all levels of youth workers. The Bi-State Core Competencies includes a five level mastery system in which levels four and five refer to skills suitable for managers and administrators. In comparison, the MDEECC Core Competencies uses a rating system that pinpoints the staffing level for which the competency is most applicable. Using the rating system, midlevel managers and administrators can easily identify the skills that they should master.

To improve the competencies available for managers and administrators, experts and practitioners should consider including skill areas that have been associated with improved practices for front-line staff (e.g. Smith et al. 2009) as well as review the competencies that were included in frameworks that address the needs of managers and administrators. Ultimately, including skills for managers in competency frameworks will also help create a career pathway for junior staff members by informing them of the skills that they will need to demonstrate to excel in higher-level positions.

Third, most of the competency frameworks are field-based. All of the frameworks that provided detail on the development process cite practitioners and experts as major sources of input and guidance. Earlier versions of competency frameworks and professional development initiatives also emerged as important field-based sources. Heavy reliance on these fieldbased sources is a strength of the frameworks because it ensures that the competencies will be relevant to the daily practice of youth workers. However, the competency frameworks neglect the potential for research to contribute to the development process.

The absence of research in the development process brings into question the ability of the frameworks to encourage youth worker practice that has been linked to positive youth outcomes. For example, research suggests that positive relationships with youth are linked to better outcomes for young people (Hall and Cassidy 2002; Pierce et al. 2010; Rosenthal and Vandell 1996). Yet, only a few competency frameworks identified interactions with youth as a competency area. It is possible that staff-youth interactions are addressed in other common competencies such as the Social and Communication competency areas but the research findings about positive interactions warrants an explicit focus in the frameworks. There is a growing body of literature that explores how staff can support positive youth outcomes (Larson et al. 2005a, 2005b; Wood et al. 2009) that should be consulted in the development of future competency frameworks.

Furthermore, omitting research from the development process resulted in competency frameworks that provide little guidance about the knowledge needed to inform the practice of youth workers. To their credit, all of the frameworks included knowledge of Child and Youth Development as a competency area that can be used to guide the development of age-appropriate activities. Beyond this, the knowledge aspect of core competencies was outweighed by a focus on practical skills. Research points to some areas of knowledge that would be beneficial for youth workers to learn. For example, research indicates that attendance at high quality programs is linked to better youth outcomes (Vandell et al. 2006) and identifies the features of high quality programs (Eccles and Gootman 2002). It seems likely that youth workers who know the features of high quality programs are better positioned to foster positive youth outcomes. Research may be particularly informative about the theories that can inform youth workers' practice (Larson and Walker 2005; Walker et al. 2005). For instance, Walker et al. (2005) proposed the Theory of Developmental Intentionality to support the design of youth development programs. Overall, it is important that competency frameworks capitalize on the experiential knowledge of experts and practitioners as well as the expanding research base on the program features and staff practices that are related to positive youth outcomes. 


\section{Conclusion}

Using a comparative analysis of a sample of competency frameworks that are currently used in youth work, this study demonstrates that there is agreement between the existing core competencies for youth workers and proposes two lists of competencies that span the diverse sectors in the OST field. These lists are a first step toward developing a clear definition of a skilled youth worker. Once refined the list(s) of common core competencies may serve as a standard that current and future youth workers can strive toward and can also be used to guide staff training.

While the shared set of competencies illustrates the agreement of experts in the OST field, more research is needed in this area. Future research should aim to: (1) help further define the competencies common to multiple sectors in the OST field; (2) understand how competencies are used by programs; and (3) examine the relationship between the competencies and implementation of high quality programs. To achieve the first research objective, analyses similar to the one conducted in this paper and by Starr et al. (2009) should be replicated with a more comprehensive sample of competency frameworks. In addition, comparative analyses between frameworks that use research in their development and those that do not could illustrate how a strong research focus can influence standards of practice.

The second and third research objectives are meant to understand if the core competencies are achieving their intended purposes. Research examining how the competencies are used in the field should determine the extent to which frameworks are used to set standards of practice and inform professional development efforts. This research could also document other, unpredicted ways in which the core competencies are used in the OST field. Finally, future research should explore if staff that have reached mastery in competency areas deliver higher quality programs than those who have not or if there are certain competencies that are more directly associated with implementing high quality program. Scholars have had some success in using quality assessment tools to relate staff practices to the quality of the program (Smith et al. 2009, 2010). For example, the Youth Program Quality Assessment (YPQA) tool, a validated observational measure, has been used to develop profiles of staff practices and to assess program quality (Smith et al. 2010). Observation tools such as the YPQA can be used to make the link between observable competencies and the implementation of quality programs.

Studies designed to address the three research aims outlined above have the potential to inform the development and use of the field-derived competency frameworks. In doing so, the experiential knowledge of experts and practitioners and the scholarly work of researchers can be joined to improve the practice of youth workers.

Acknowledgments I would like to thank Marion W. Pines for her guidance and for reviewing early drafts of this paper.

Open Access This article is distributed under the terms of the Creative Commons Attribution Noncommercial License which permits any noncommercial use, distribution, and reproduction in any medium, provided the original author(s) and source are credited.

\section{References}

Academy for Educational Development Center for Youth Development and Policy Research. (1996). Core competencies for national youth serving organizations. Washington, DC: Academy for Educational Development Center for Youth Development and Policy Research. 
Advancing Careers through Education and Training. (1995). Professional development competencies. Retrieved on April 2, 2007 from http://www.acetonline.org/professional.pdf.

Advancing Careers through Education and Training. (2007). The Georgia early care and education professional development competencies: School-age care professional. Retrieved November 29, 2009 from http://www.acetonline.org/training_competencies.htm.

Advancing Careers through Education and Training. (n.d.) Advancing Careers through Education and Training-ACET. Retrieved on April 2, 2007 from http://www.acetonline.org/index.html.

Afterschool Works! New York (2009). New York school age care credential: 2009-2010 manual. Retrieved December 20, 2009 from http://www.afterschoolworksny.org/saccmanual.html.

Astroth, K., Garza, P., \& Taylor, B. (2004). Getting down to business: Defining competencies for entry-level youth workers. New Directions for Youth Development, 104, 25-37.

Bodilly, S., \& Beckett, M. (2005). Making out-of-school time matter: Evidence for an action agenda. Santa Monica, CA: Rand Corporation.

Bouffard, S., \& Little, P. (2004). Promoting quality through professional development: A framework for evaluation. Issues and Opportunities in Out-of-School Time Evaluation, 8, 1-11.

Bowie, L., \& Bronte-Tinkew, J. (2006). The importance of professional development for youth workers (Publication \#2006-17) Washington. DC: Child Trends.

Campbell, N., Applebaum, J., Martinson, K., \& Martin, E. (2000). Be all that we can be: Lessons from the military for improving our nation's child care. Washington, DC: National Women's Law Center.

Charles Stewart Mott Foundation Committee on After School Research and Practice. (2005). Moving toward success: Framework for after school programs. Washington, DC: Collaborative Communications Group.

Commonwealth Youth Programme. (2006a). The commonwealth diploma in youth development. London: Commonwealth Youth Programme.

Commonwealth Youth Programme. (2006b). Stimulating excellence in youth work. London: Commonwealth Youth Programme.

Community Matters, \& Breslin, T. (2003). Workforce development in out-of-school time: Lessons learned and innovative strategies. Providence, RI: Rhode Island KIDS COUNT.

Dennehy, J., \& Noam, G. (2005). Evidence for action: Strengthening after-school programs for all children and youth: The Massachusetts out-of-school time workforce. Boston: Achieve Boston and Initiative of Boston After School \& Beyond.

Department of the Air Force. (1998). Air Force manual 34-251: Air Force school-age programs. Pentagon City, VA: Department of the Air Force.

Durlak, J., \& Weissberg, R. (2007). The impact of after-school programs that promote personal and social skills. Chicago, IL: Collaborative for Academic, Social, and Emotional Learning.

Eccles, J., \& Gootman, J. (2002). Community programs to promote youth development. Washington, DC: National Academies Press.

Grossman, J., Price, M., Fellerath, V., Jucovy, L., Kotloff, J., Raley, R., et al. (2002). Multiple choices after school: Findings from the extended-service schools initiative (No. 48). Philadelphia: MDRC.

Hall, A., \& Cassidy, D. (2002). An assessment of the North Carolina school-age care accreditation initiative. Journal of Research in Childhood Education, 17, 84-97.

Howes, C. (1997). Children's experiences in center-based child care as a function of teacher background and adult:child ratio. Merrill-Palmer Quarterly, 43, 404-425.

Indiana YouthPRO Association. (2005). Core competencies for Indiana Youth Development Credential. Retrieved on April 2, 2007 from http://www.indianayouthpro.org/IYD/competencies.htm.

Indiana YouthPRO Association. (2007). The Indiana youth development credential. Retrieved on April 2, 2007 from http://www.indianayouthpro.org/iyd.htm.

Larson, R., Hansen, D., \& Walker, K. (2005a). Everybody's gotta give: Development of initiative and teamwork within a youth program. In J. Mahoney, R. Larson, \& J. Eccles (Eds.), Organized activities as contest of development: Extracurricular activities, after-school and community programs (pp. 159-184). Mahway, NJ: Lawrence Erlbaum Associates.

Larson, R., \& Walker, K. (2005). Processes of positive development: Classic theories. In P. Witt \& L. Caldwell (Eds.), Recreation and youth development. State College, PA: Venture Publishing.

Larson, R., Walker, K., \& Pearce, N. (2005b). A comparison of youth-driven and adult-driven youth programs: Balancing inputs from youth and adults. Journal of Community Psychology, 33(1), 57-74.

Little, P. (2004). A recipe for quality out-of-school time programs. The Evaluation Exchange, 10(1), 18-19.

Little, P. (2007). The quality of school-age child care in after-school settings. Research-to-Policy Connections, 7. Washington, DC: Child Care and Early Education Research Connections.

Little, P., \& Harris, E. (2003). A review of out-of-school time program quasi-experimental and experimental evaluation results (No. 1). Cambridge, MA: Harvard Family Research Project. 
Madzey-Akale, J., \& Walker, J. (2000). Training needs and professional development interests of Twin Cities youth workers: Summary. Minneapolis, MN: Regents of the University of Minnesota.

Massachusetts Department of Early Education and Care. (2010). Core competencies for early education and care and out-of-school time educators. Boston, MA: Massachusetts Department of Early Education and Care.

McCain, M., Gill, P., Wills, J., \& Larson, M. (2004). Knowledge, skills and abilities of youth service practitioners: The centerpiece of a successful workforce development system. Washington, DC: National Collaborative on Workforce and Disability for Youth.

Miller, B. (2003). Critical hours: After school programs and educational success. Brookline, MA: Nellie Mae Foundation.

National Afterschool Association. (2006). Understanding the afterschcool workforce: Opportunities and challenges for an emerging profession. Houston, TX: Cornerstones for Kids.

National Collaboration for Youth (2004). Youth development worker competencies. Retrieved on April 19, 2007 from http://www.nydic.org/nydic/staffing/profdevelopment.htm.

National Collaboration for Youth. (n.d.). National youth development information center. Retrieved April 1, 2007 from http://www.nydic.org/nydic/about/index.htm.

National Institute for Child Health and Development and Early Child Care Research Network. (2001). Nonmaternal care and family factors in early development: An overview of the NICHD study of early child care. Applied Developmental Psychology, 22, 457-492.

National Institute for Out-of-School Time, \& Academy for Educational Development Center for Youth Development and Policy Research. (2003). Strategic plan: Building a skilled and stable out-of-school time workforce. Wellesley, MA: Authors.

National Institute on Out-of-School Time. (2003). Making the case: A fact sheet on children and youth in out-of-school time. Wellesley, MA: National Institute on Out-of-School Time.

National Institute on Out-of-School Time. (2006). The human services workforce initiative: Setting the stage for a youth development credential. Houston, TX: Cornerstones for Kids.

New York State School Age Care Coalition, New York State Office of Children and Family Services, \& Cornell University. (2000). New York State school-age care credential. New York: Authors.

Nonyongo, E. (2006). Commonwealth diploma in youth development: The UniSA case study. In A. Hope \& P. Guiton (Eds.), Strategies for sustainable and open distance learning: Vol. 6. Worldview of distance education and open learning. New York: Taylor and Francis Inc.

Norris, D. (2001). The quality of care offered by provider with differential patterns of workshop participation. Child \& Youth Care Forum, 30, 111-112.

Opportunities in a Professional Education Network Initiative in Missouri, Missouri Afterschool Network, \& Kansas Enrichment Network. (2006). Kansas and Missouri core competencies for youth development professionals (1st ed.). Columbia, MO: Authors.

Peisner-Feinberg, E., Burchinal, M., Clifford, R., Yazejian, N., Culken, M., Zelazo, J., et al. (2000). The children of the cost, quality, and outcomes study go to school: Technical report. Chapel Hill, NC: University of North Carolina at Chapel Hill and Frank Porter Graham Child Development Center.

Phillipsen, L., Burchinal, M., Howes, C., \& Cryer, D. (1997). The prediction of process quality from structural features of child care. Early Childhood Research Quarterly, 12, 281-303.

Pierce, K., Bolt, D., \& Vandell, D. (2010). Specific features of after-school program quality: Differential associations with children's functioning in middle childhood. American Journal of Community Psychology, 45, 381-393.

Rosenthal, R., \& Vandell, D. (1996). Quality of care at school-aged child-care programs: Regulatable features, observed experiences, child perspectives, and parent perspectives. Child Development, 67, 2434-2445.

Sar Levitan Center. (2001). Youth development practitioner apprenticeship: Guide for building a skilled youth development workforce. Baltimore, MD: Authors.

Smith, C., Pearson, L., Peck, S., Denault, A., \& Sugar, S. (2009). Managing for positive youth development: Linking practices to instructional performances in out-of-school time organizations. Paper presented at the annual meeting of the American Educational Research Association, San Diego, CA.

Smith, C., Peck, S., Denault, A., Blazevski, J., \& Akiva, T. (2010). Quality at the point of service: Profiles of practice in after school settings. American Journal of Community Psychology, 45, 358-369.

Starr, B., Yohalem, N., \& Gannett, E. (2009). Youth worker core competencies: A review of existing frameworks and purposes. Washington DC: Next Generation Youth Work Coalition.

Stone, B., Garza, P., \& Borden, L. (2004). Attracting, Developing \& Retaining Youth Workers for the Next Generation. Wingspread Conference: National Collaboration for Youth, National 4-H Headquarters, CSREES, USDA, University of Arizona School of Family and Consumer Science. 
Tolman, J., Pittman, K., Yohalem, N., Thomases, J., \& Trammel, M. (2002). Moving and Out-of-School Agenda: Lessons and challenges across cities (Task Brief \#2). Takoma Park, MD: Forum for Youth Investment.

United States Department of Labor. (2009). Youth development practitioner apprenticeship (YDPA) initiative (SGA/DFA 02-110), employment \& training administration (ETA)-U.S. Department of Labor. Retrieved December 18, 2009 from http://www.doleta.gov/grants/sga/02-110sga.cfm.

Vandell, D., Reisner, E., Brown, B., Dadisman, K., Pierce, K., Lee, D., et al. (2006). The study of promising after-school programs: Examination of longer term outcomes after two years of program experiences. Madison, WI: Wisconsin Center for Education Research.

Vandell, D., Reisner, E., Brown, B., Dadisman, K., Pierce, K., Lee, D., et al. (2005). The study of promising after-school programs: Examination of intermediate outcomes in Year 2. Madison, WI: Wisconsin Center for Education Research.

Vandell, D., Reisner, E., Brown, B., Pierce, K., Dadisman, K., \& Pechman, E. (2004). The study of promising after school programs: Descriptive report of the promising programs. Madison, WI: Wisconsin Center for Education Research.

Vandell, D., \& Wolf, B. (2000). Child care quality: Does it matter and does it need to be improved? (Special Report No. 78). Madison, WI: Institute for Research on Poverty.

Walker, J., Marczak, M., Blyth, D., \& Borden, L. (2005). Designing youth development programs: Toward a theory of developmental intentionality. In J. Mahoney, R. Larson, \& J. Eccles (Eds.), Organized activities as contexts of development: Extracurricular activities, after-school and community programs (pp. 399-419). Mahway, NJ: Lawrence Erlbaum Associates.

Wood, D., Larson, R., \& Brown, J. (2009). How adolescents come to see themselves as more responsible through participation in youth programs. Child Development, 80(1), 295-309.

Yohalem, N., Pittman, K., \& Moore, D. (2006). Growing the next generation of youth professionals: Workforce opportunities and challenges. Houston, TX: Cornerstones for Kids. 